\title{
Nanostructured catalysts for BIOEthanol transformation to industrially important chemicals
}

\author{
Blažej Horváth ${ }^{1}$, Matúš Petrík ${ }^{2}$, Dana Gašparovičová ${ }^{1}$, Tomáš Soták ${ }^{1}$ \\ ${ }^{1}$ Department of Organic Technology, Catalysis and Petroleum Chemistry, Institute of Organic Chemistry, \\ Catalysis and Petrochemistry, Faculty of Chemical and Food Technology, \\ Slovak University of Technology in Bratislava, \\ Radlinského 9, 81237 Bratislava, Slovak Republic \\ ${ }^{2}$ Fortischem a.s., M. R. Štefánika 1, 97271 Nováky, Slovak Republic \\ blazej.horvath@stuba.sk
}

\begin{abstract}
Utilization of a low-cost biomaterial, such as bioethanol, to produce value-added compounds for current industry has been investigated. This work is focused on the catalytic transformation of bioethanol into industrially significant alkenes. Catalytic transformation of ethanol was studied using catalysts based mainly on nanostructured materials as $\mathrm{Mg}$-Al hydrotalcites, sepiolites and zeolites doped with $\mathrm{Cu}, \mathrm{K}, \mathrm{Sr}, \mathrm{Zn}$ and $\mathrm{Mn}$. The catalytic tests were carried out in a plug-flow reactor in the temperature range of $350-550{ }^{\circ} \mathrm{C}$. Undoped zeolites promote acid-catalyzed dehydration of ethanol, while in case of basic catalysts, such as hydrotalcites, the product distribution is shifted toward butadiene. The impact of the hydrotalcites preparation method on their structure and catalytic activity is reported. It was found that hydrotalcite with well-developed layered structure, prepared by slow hydrolysis, promotes the formation of butadiene (with butadiene yield of $28.2 \%$ at $400{ }^{\circ} \mathrm{C}$ vs. ethylene yield of $17.2 \%$ at $550{ }^{\circ} \mathrm{C}$ ).
\end{abstract}

Keywords: acetaldehyde, butadiene, catalyst, ethanol, hydrotalcites

\section{Introduction}

Currently, emphasis has been given to the production of chemicals from renewable sources. The reason is the ever-increasing global pollution and the fact that fossil fuel reserves are being depleted. Bioethanol is a liquid biofuel obtained from biomass by biochemical transformation.

Ethanol is widely used in beverages but also in the chemical industry as a solvent or a suitable raw material for the production of other important chemicals.

Butadiene is historically one of the most important industrial substances, mainly for its use in the production of elastomers (production of tires). Prior to the invention of butadiene polymerization technology, the only way to produce tire elastomers was to vulcanize natural caoutchouc, which economically favored countries with colonial roots extending into tropical areas where rubber trees grow. Other countries therefore turned to butadiene after Lebedev discovered that it could be polymerized into rubber-like polymers (Pomalaza et al., 2020; Egloff, 1945). In 1915, Ostromyslensky synthesized considerable amounts of butadiene by the reaction of ethanol and acetaldehyde on alumino-clay catalysts (Lebedev, 1929). Both processes - Ostromyslensky and Lebedev - became the basis of large-scale industrial processes. In the
United States, Union Carbide and Carbon Chemical Corporation, in collaboration with the Mellon Research Institute, conducted extensive studies of the ethanol-butadiene conversion process, including catalyst research (Corson et al., 1950), process optimization (Kampmeyer and Stahly, 1949) and mechanistic studies (Jones et al., 1949). After World War II, and with the increasing availability of cheap butadiene from oil cracking, this process gradually declined. Recently, however, there has been a resurgence of academic interest in this process, driven mainly by economic (price of crude oil) and environmental factors (crude oil is a non-renewable raw material, $\mathrm{CO}_{2}$ emissions).

There is a relatively well-established opinion on the reaction mechanism of ethanol conversion to butadiene. In the first reaction step, in an acid- or metal- catalyzed reaction, ethanol is dehydrogenated to acetaldehyde. Subsequently, in the second condensation - dehydration step, acetaldehyde reacts with unreacted ethanol, which leads to the formation of butadiene (Akiyama et al., 2018).

$$
\begin{gathered}
\mathrm{C}_{2} \mathrm{H}_{5} \mathrm{OH} \rightarrow \mathrm{CH}_{3} \mathrm{CHO}+\mathrm{H}_{2} \\
\mathrm{C}_{2} \mathrm{H}_{5} \mathrm{OH}+\mathrm{CH}_{3} \mathrm{CHO} \rightarrow \mathrm{CH}_{2} \mathrm{CHCHCH}_{2}+2 \mathrm{H}_{2} \mathrm{O}
\end{gathered}
$$

Nowadays, technologies for the catalytic dehydrogenation of ethanol already have been commercialized (Tayrabekova at al., 2018), however, finding 
a suitable basic catalyst for the condensation of ethanol with acetaldehyde continues to be a challenge.

Therefore, our research has mainly focused on finding suitable basic nanostructured catalysts, especially hydrotalcites and sepiolites. For the sake of completeness, zeolitic catalysts are briefly discussed as well. In this work, the possibilities of catalytic conversion of ethanol to industrially important alkenes, which are up to now mostly obtained from fossil fuels, is discussed. These alkenes include ethylene, propylene and 1,3-butadiene. A series of acidic and basic catalysts (parent or doped with transition metals) were tested for this reaction.

\section{Hydrotalcites}

Hydrotalcites, also known as layered double hydroxides or Feitknecht compounds, with the general formula: $\mathrm{M}^{2+}{ }_{1-\mathrm{x}} \mathrm{M}^{3+}{ }_{\mathrm{x}}(\mathrm{OH})_{2}\left(\mathrm{~A}^{\mathrm{n}-}\right)_{\mathrm{x} / \mathrm{n}} \cdot \mathrm{mH}_{2} \mathrm{O}$, where $\mathrm{M}^{2+}$ and $\mathrm{M}^{3+}$ are divalent (e.g., $\mathrm{Mg}, \mathrm{Ni}, \mathrm{Zn}, \mathrm{Cu}, \mathrm{Mn}$ ) and trivalent (e.g., $\mathrm{Al}, \mathrm{Fe}, \mathrm{Cr}$ ) metal ions, $\mathrm{A}^{\mathrm{n}-}$ is an anion (most commonly $\mathrm{CO}_{3}^{2-}$, but also $\mathrm{SO}_{4}^{2-}, \mathrm{NO}_{3}^{-}, \mathrm{Cl}^{-}$, $\mathrm{OH}^{-}$), and the value of $\mathrm{x}$ is $0.1-0.5$. Hydrotalcites have similar structure as the mineral brucite, where metal ions are deployed in an octahedrally coordinated hydroxide layer, while anions and molecules of water are held in an anionic interlayer. Positive charge of the metal ion layer is compensated by the negative charge of the interlayer (Benhiti et al., 2020).

The most common hydrotalcite has the formula: $\mathrm{Mg}_{0.75} \mathrm{Al}_{0.25}(\mathrm{OH})_{2}\left(\mathrm{CO}_{3}\right)_{0.125} \cdot 0.5 \mathrm{H}_{2} \mathrm{O}$. The layers are stocked on each other, while the thickness of one layer is $0.48 \mathrm{~nm}$ and the bond length of $\mathrm{Mg}-\mathrm{O}$ is $0.21 \mathrm{~nm}$. Hydrotalcites are sought-after materials for their high surface area, acid-base properties, and structural stability. Hydrotalcites have also received increasing attention due to their cheap and easy synthesis. Their acid-base properties depend on their chemical composition and the methods of their preparation (Rackley et al., 2017).

Hydrotalcites decompose gradually upon heating. In the first stage, in the temperature range of
$30-250{ }^{\circ} \mathrm{C}$, the loss of water molecules held in the interlayer occurs. During the second stage, ranging from $300{ }^{\circ} \mathrm{C}$ to $500{ }^{\circ} \mathrm{C}$, dehydroxylation takes place. Increasing the calcination temperature up to $700{ }^{\circ} \mathrm{C}$ leads to decarbonation and the material is decomposed to $\mathrm{MgO}$ and $\mathrm{MgAl}_{2} \mathrm{O}_{4}$ (Sikander et al., 2017).

\section{Coprecipitation method}

The coprecipitation method is a common hydrotalcites synthesis method, where inorganic $\mathrm{Mg}$ and $\mathrm{Al}$ salts are supersatured in alkaline media either at increasing $\mathrm{pH}$ or at constant $\mathrm{pH}$. Supersaturation is achieved by evaporation (physical method) or by adjusting the $\mathrm{pH}$ (chemical method). The $\mathrm{pH}$ value has to be chosen wisely, if it is too high, aluminum ions leak by forming soluble aluminates, if it is too low, precipitation of all metallic ions may not occur. High crystallinity is achieved in case of low supersaturation (slow precipitation). Solution of an alkaline agent, e.g. $\mathrm{NaOH}$ or $\mathrm{Na}_{2} \mathrm{CO}_{3}$, is used to maintain the $\mathrm{pH}$ value typically at 10 . The mixture is usually stirred for a prolonged period of time at elevated temperature, usually at $60^{\circ} \mathrm{C}$. Precipitates are then filtered, washed and dried. Catalytic properties of hydrotalcites are influenced by $\mathrm{pH}$, the nature of cations and anions, ratio of metal cations, aging time and temperature (Sikander et al., 2017). Catalytic conversion of ethanol using hydrotalcites was provided by the coprecipitation method. The authors synthesized hydrotalcites at low and high supersaturation using sonication at the $\mathrm{Mg}^{2+}$ to $\mathrm{Al}^{3+}$ molar ratio of $3 / 1$ either at constant or variable $\mathrm{pH}$. Stronger basic sites were reported in case of catalysts prepared at high supersaturation conditions, along with more favorable product distribution when using these catalysts for ethanol condensation (León et al., 2010).

\section{Urea hydrolysis}

Another precipitating agent can be urea; it hydrolyzes slowly at elevated temperature releasing ammonia and carbonate anion, which leads to slow supersaturation. Slow supersaturation generally
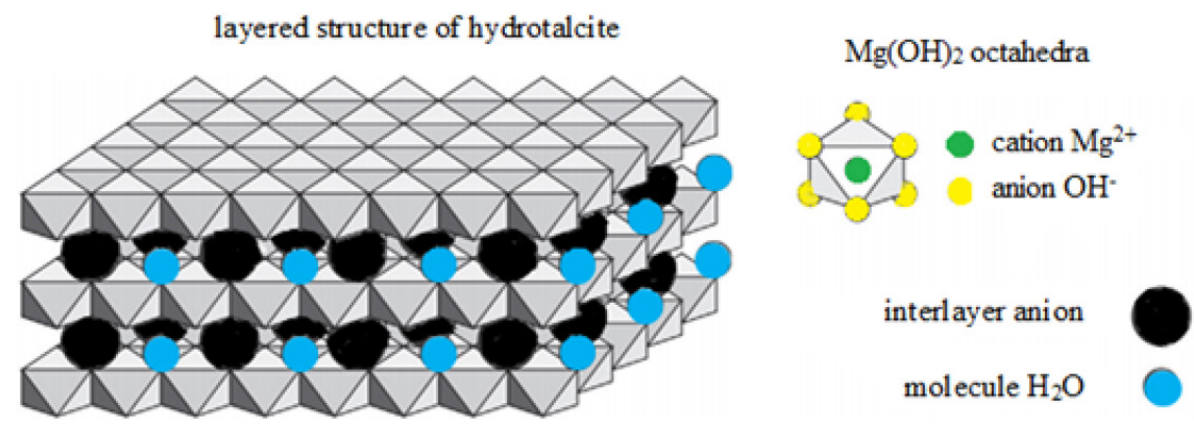

Fig. 1. Layered structure of hydrotalcite (Rackley, 2017). 
allows the formation of a better developed crystal structure. Hydrolysis of urea yields ammonium cyanate or its ions as well. Another advantage of using urea is the simple washing compared to alkalines, where repeated washing is required to remove alkaline ions (Sikander et al., 2017).

Hydrotalcites were synthesized in an autoclave using different molar ratios of metals to urea. Urea with aqueous solution of nitrates of $\mathrm{Mg}$ and $\mathrm{Al}$ was used at $180{ }^{\circ} \mathrm{C}$ in $2 \mathrm{~h}$ under vigorous stirring. The precipitate was filtered, washed, and dried at $120{ }^{\circ} \mathrm{C}$ overnight. To obtain hydrotalcite with the least $\mathrm{MgCO}_{3}$ or aluminates contamination, molar ratio of $\mathrm{Mg}: \mathrm{Al}$ in the range of $2-3$ in the metal nitrate precursors has been reported to be the most suitable (Mohan et al., 2005).

\section{Sol-gel method}

Sol-gel method is reported to lead to hydrotalcites of high phase purity. The specific surface area of thus-synthesized materials can reach $150 \mathrm{~m}^{2} \cdot \mathrm{g}^{-1}$ or higher (Sikander et al., 2017). Decreasing the precipitation temperature was reported to have beneficial effect in terms of the specific surface area of the as-synthesized material (Federica et al., 2000).

\section{Combustion Synthesis}

During combustion synthesis, explosive decomposition of organometallic precursors takes place leading to the formation of mixed metal oxides. Hydrotalcites have a peculiar feature known as the memory effect which allows (re)generation of layered structure from mixed oxides to (re)gain the hydrotalcite structure (Basahel et al., 2014).

\section{Microwave treatment}

Using microwave treatment in the above-mentioned synthesis methods not only reduces the synthesis time but also decreases the crystallite size (Sikander et al., 2017).

\section{Hydrothermal Treatment}

Hydrothermal treatment in the presence of water vapor improves the crystal size of hydrotalcites. Such treatment also maintains or compensates water molecules in the interlayer, which could be lost in the previous stages of preparation. This method also increases crystalline sizes of hydrotalcites (Basahel et al., 2014).

\section{Sepiolites}

Sepiolite is a silicate clay mineral consisting of silica-oxygen tetrahedrons and magnesium-oxygen octahedrons. In its structure, channels $(1.06 \mathrm{~nm}$ $\times 0.37 \mathrm{~nm})$ filled with molecules of water and exchangeable cations can be found. Sepiolites are characterized by their high surface area up to approximately $800-900 \mathrm{~m}^{2} \cdot \mathrm{g}^{-1}$, with ca. $400 \mathrm{~m}^{2} \cdot \mathrm{g}^{-1}$ representing the external surface and $500 \mathrm{~m}^{2} \cdot \mathrm{g}^{-1}$ the internal surface area (Tian et al., 2019).

\section{Recent advances in the field of potential catalysts for ethanol conversion}

Ethanol conversion to butadiene was studied over mesoporous $\mathrm{MgO}-\mathrm{SiO}_{2}$ catalysts promoted by $\mathrm{In}_{2} \mathrm{O}_{3}$ (Szabó et al., 2020). Four samples of the support were prepared: one sample was prepared by wet impregnation of SBA-15 with magnesium nitrate, one sample was prepared by kneading a paste of magnesium hydroxide and SBA-15, and two samples were prepared by one-step synthesis using methoxide or ethoxide as a precursor, the support samples were subsequently impregnated with indium-containing precursors. Catalyst samples were characterized and used for ethanol transformation in a fixed bed glass microreactor in the temperature range of $250-450{ }^{\circ} \mathrm{C}$. The results obtained showed that the selectivity of undoped catalysts for butadiene were $10-30 \%$, with the main reaction products being diethyl ether at lower $\left(250-300\right.$ to $325^{\circ} \mathrm{C}$ ) and ethylene at higher temperatures $\left(300-325^{\circ} \mathrm{C}\right.$ to $450{ }^{\circ} \mathrm{C}$ ). An addition of $\operatorname{In}_{2} \mathrm{O}_{3}$ to the catalysts increased their selectivity to butadiene up to $60 \%$. The addition of indium was also shown to suppress ethanol dehydration to ethylene.

Two types of catalysts containing zinc oxides and cerium were prepared (Zhao et al., 2019). The mesoporous support SBA-15 was prepared by hydrothermal synthesis using organic template Pluronic 123. Such prepared material was washed, dried and subsequently calcined. The catalysts were then characterized, and their catalytic activity was investigated in the synthesis of butadiene from ethanol at $375^{\circ} \mathrm{C}$ and $1.62 \mathrm{~g} \cdot \mathrm{h}^{-1}$ of ethanol. The obtained data show that the catalyst prepared using a templated support had higher conversion and selectivity to butadiene. Characterization of the catalysts revealed that both zinc and cerium atoms were predominantly dispersed in the mesopores of the support, but in case of the catalyst with a calcined support, higher aggregation of cerium oxides and pore blockage occurred. The authors suggest that the presence of an organic template promotes even distribution of zinc and cerium atoms and thus an increase in the number of acidobasic centers, better preservation of the mesoporous structure of the support, and increased catalytic activity.

Three $\mathrm{MgO}-\mathrm{SiO}_{2}$ catalysts with unique structure and morphology were prepared and studied (Li et al., 2019). These catalysts were prepared by reverse impregnation (loading of $\mathrm{SiO}_{2}$ sol on $\mathrm{MgO}$ support) applying hydrothermal synthesis using surfactants. 
Three support structures have been reported. The 'flower-like' shape was achieved by dissolving magnesium acetate in ethylene glycol adding polyvinylpyrrolidone as a surfactant, and then autoclaving at $180{ }^{\circ} \mathrm{C}$. Nanodisc and nanosheet shapes were achieved by precipitation of magnesium chloride dissolved together with EDTA and benzoic acid. Various shapes indicate that the precursor affected the morphology and the activity of the resulting catalyst, with larger pore size and higher portion of basic sites promoting ethanol dehydrogenation and aldol condensation while suppressing ethanol dehydration to ethylene.

Ordered mesoporous materials such as zinc and zirconium oxide catalysts were synthesized to increase butadiene yields (Ahn et al., 2020). Mesoporous silicas were prepared using Pluronic 123 in butanol as a template. It was shown that as-prepared catalysts gave high yields of butadiene. Amorphous silica, on the other hand, gave acetaldehyde as the main product, and the alumina-based catalysts preferred diethyl ether formation. Alumina-based catalysts contained a large number of $\mathrm{Al}^{3+}$ acid centers, which led to ethanol dehydration to diethyl ether and ethylene.

The effect of calcination temperature on the acidbase properties of catalysts and their catalytic activity in the butadiene synthesis from ethanol/acetaldehyde mixture was investigated. $\mathrm{ZrO}_{2} /$ nanosilica catalysts prepared by dry impregnation of nanosilica with zirconium nitrate and ultrasonic treatment of the resulting samples served as catalyst samples (Gao et al., 2018), which were then calcined in the temperature range of $450-700{ }^{\circ} \mathrm{C}$. The incidence of acidic centers has been shown to decrease with the increasing calcination temperature. The number of basic centers, in turn, first increased with the increasing temperature and then gradually decreased. The main reaction products were butadiene, ethene, ethers, ethyl acetate, propene, and butanol. Comparison of the catalytic activity showed that with the increasing calcination temperature, the conversion of raw material increased at first, $\left(29.4 \%\right.$ at $\left.450{ }^{\circ} \mathrm{C}\right)$, reached a maximum at $600{ }^{\circ} \mathrm{C}(58.9 \%)$ and then decreased $\left(47.3 \%\right.$ at $\left.700{ }^{\circ} \mathrm{C}\right)$.

The influence of structural parameters of mesoporous zeolites on ethanol conversion was analyzed (Klein et al., 2017). This study focuses on the formation of an additional mesoporous system in zeolites. Zeolite samples were synthesized by two methods: the top-down method based on desilication of zeolite $\beta$ and the bottom-up method based on organosilicate templates. This led to the conclusion that, in addition to the acid-base properties of the catalyst, also crystal structure is important for ethanol conversion.
Zinc-containing talc was used as a catalyst (Sekiguchi et al., 2015). Five catalyst samples were prepared: (I-III) along with three commercial Zn-talc samples, (IV) a zinc-free talc sample was prepared, and (V) one binary $\mathrm{MgO}-\mathrm{SiO}_{2}$ catalyst was prepared by kneading magnesium hydroxide gel and colloidal silica. Catalytic tests were performed in a continuous plug-flow reactor at atmospheric pressure and the temperature of $400{ }^{\circ} \mathrm{C}$. It has been shown that the catalyst activity strongly depends on the presence and amount of zinc in the catalyst, although the structure of the catalysts was very similar. The presence of zinc also extended the lifespan of the catalyst.

\section{Experimental}

\section{Catalyst preparation}

$\mathrm{Cu}\left(\mathrm{NO}_{3}\right)_{2} \cdot 3 \mathrm{H}_{2} \mathrm{O}, \quad \mathrm{Mg}\left(\mathrm{NO}_{3}\right)_{2} \cdot 6 \mathrm{H}_{2} \mathrm{O}$ and $\mathrm{Al}\left(\mathrm{NO}_{3}\right)_{3} \cdot 9 \mathrm{H}_{2} \mathrm{O}$ (Merck) were used as metal precursors. Copper was reported to be a suitable metal component of the catalysts for ethanol dehydrogenation to acetaldehyde (Pampararo et al., 2020). Therefore, several catalysts were doped with copper by the wet impregnation method using a $3 \%$ solution of copper nitrate so that the copper content of the resulting material was $5 \%$ (calculated as $\mathrm{CuO}$, indicated as a $-5 \mathrm{Cu}$ suffix in the catalyst codename; suffixes indicate the metal oxide content in per cents).

If not otherwise specified, the catalyst samples were subsequently calcined in static air at $500{ }^{\circ} \mathrm{C}$ to convert copper nitrate to oxidic form. $\mathrm{Mg}$ and $\mathrm{Zn}$ were loaded on the zeolitic catalysts analogously, using the corresponding nitrate precursors.

Microstructured Faujasite type 13Y (SK-40) $\left(\mathrm{SiO}_{2} / \mathrm{Al}_{2} \mathbf{O}_{3}\right.$ Mole Ratio: 5) (provided by $\mathrm{VU}$ RUP, a.s.), USY ( $\mathbf{S i O}_{2} / \mathbf{A l}_{2} \mathbf{O}_{3}$ Mole Ratio: 2.6), mesostructured MCM-22 $\quad\left(\mathbf{S i O}_{2} / \mathbf{A l}_{2} \mathbf{O}_{3} \quad\right.$ Mole

Ratio: 15) (Zeolyst) were used as supports for the zeolite-based catalysts. Characterization of these MCM-22 and USY samples (see Table 1) is given in our previous work (Soták et al., 2021).

Table 1: Several textural and acidobasic parameters for selected catalysts.

\begin{tabular}{lcc}
\hline Parameter $/$ Sample & MCM-22 & USY \\
\hline $\mathrm{S}_{\mathrm{BET}} / \mathrm{m}^{2} \mathrm{~g}^{-1}$ & 547 & 685 \\
$\mathrm{~S}_{\mathrm{EXT}} / \mathrm{m}^{2} \mathrm{~g}^{-1}$ & 158 & 84 \\
$\mathrm{~V}_{\text {micro }} / \mathrm{cm}^{3} \mathrm{~g}^{-1}$ & 0.19 & 0.27 \\
$\mathrm{~V}_{\text {tot }} / \mathrm{cm}^{3} \mathrm{~g}^{-1}$ & 0.43 & 0.38 \\
$\mathrm{~B}_{\mathrm{ac}} / \mu \mathrm{molg}^{-1}$ & 390 & 480 \\
$\mathrm{~L}_{\mathrm{ac}} / \mu \mathrm{molg}^{-1}$ & 310 & 1010 \\
\hline
\end{tabular}

Note: $\mathrm{S}_{\mathrm{BET}}-\mathrm{BET}$ surface area, $\mathrm{S}_{\mathrm{EXT}}$ external surface area, $\mathrm{V}_{\text {micro }}$ - micropore volume, $\mathrm{V}_{\text {tot }}-$ total pore volume, $\mathrm{B}_{\mathrm{ac}}-$ Brönsted acidity, $\mathrm{L}_{\mathrm{ac}}$ - Lewis acidity. 
To prepare sepiolite-based catalysts, commercial sepiolite (Sigma) was impregnated with metal nitrate solutions following the above-mentioned procedure.

Hydrotalcite-based catalysts were prepared using a co-precipitation method, $0.1 \mathrm{M}$ solutions of magnesium nitrate and aluminum nitrate were added simultaneously to a $0.2 \mathrm{M}$ solution of $\mathrm{Na}_{2} \mathrm{CO}_{3}$ dropwise at the temperature of $65^{\circ} \mathrm{C}$ under vigorous stirring. $\mathrm{pH}$ of the mixture was adjusted to $10 \pm 0.1$ during the precipitation adding appropriate amounts of a $0.2 \mathrm{M} \mathrm{NaOH}$ solution. After the precipitation, the suspension was mixed overnight, filtered, washed with deionized water, and dried at $110{ }^{\circ} \mathrm{C}$ overnight. Molar ratios of $\mathrm{Mg}$ : Al precursors used in different samples were 3:1 and 0.5:1, respectively. To prepare hydrotalcite-based catalysts by the urea method, instead of sodium carbonate and sodium hydroxide, urea was added to the solution of $\mathrm{Al}$ and $\mathrm{Mg}$ nitrates in the molar ratio of urea: $(\mathrm{Mg}+\mathrm{Al})=4: 1$. The mixture was refluxed for $24 \mathrm{~h}$, filtered, washed and dried at $110^{\circ} \mathrm{C}$ overnight. The dehydration-rehydration process of hydrotalcites was carried out by calcining the parent sample in static air at $550{ }^{\circ} \mathrm{C}$; the sample was then cooled down to laboratory temperature, loaded with deionized water by the incipient wetness method, and aged in static air for 30 days.
Templated hydrotalcite-like materials were prepared by the precipitation method with an addition of Pluronic123 surfactant (Sigma) along with n-octane. The saturated solution of particular nitrates was added dropwise to a mixture of ethanol, Pluronic 123 and n-octane with the mass ratio Pluronic123:octane:ethanol $=1: 1: 1$. $\mathrm{pH}$ of the mixture was kept at $10 \pm 0.1$ by adding appropriate amounts of saturated ammonia solution. After aging for $24 \mathrm{~h}$, the precipitate was washed with an excess of methanol.

The SEM measurement was carried out on a Zeiss EVO 40 microscope and XRD patterns were recorded using a Philips PW1349/30 diffractometer utilizing Co $\mathrm{K}_{\alpha}$ radiation.

\section{Catalyst testing}

Bioethanol (food grade refined spirit, $\geq 96 \%$ ) as a reactant was injected at the flow rate of $5 \mathrm{ml} \cdot \mathrm{h}^{-1}$ by a syringe pump. Ethanol was drifted in a flow of a carrier gas $-\mathrm{N}_{2}$, at the flow rate of $100 \mathrm{ml} \cdot \mathrm{min}^{-1}$ into a fixed bed inox reactor where $2.8 \mathrm{ml}$ of catalyst granulate with the grain size of $0.1-0.3 \mathrm{~mm}$ was used. Catalytic tests were carried out in the temperature range from $350{ }^{\circ} \mathrm{C}$ to $550{ }^{\circ} \mathrm{C}$. Temperature was controlled using a J type thermocouple connected to a PID controller and an electric heating mantle. The reaction products, along with unreacted etha-

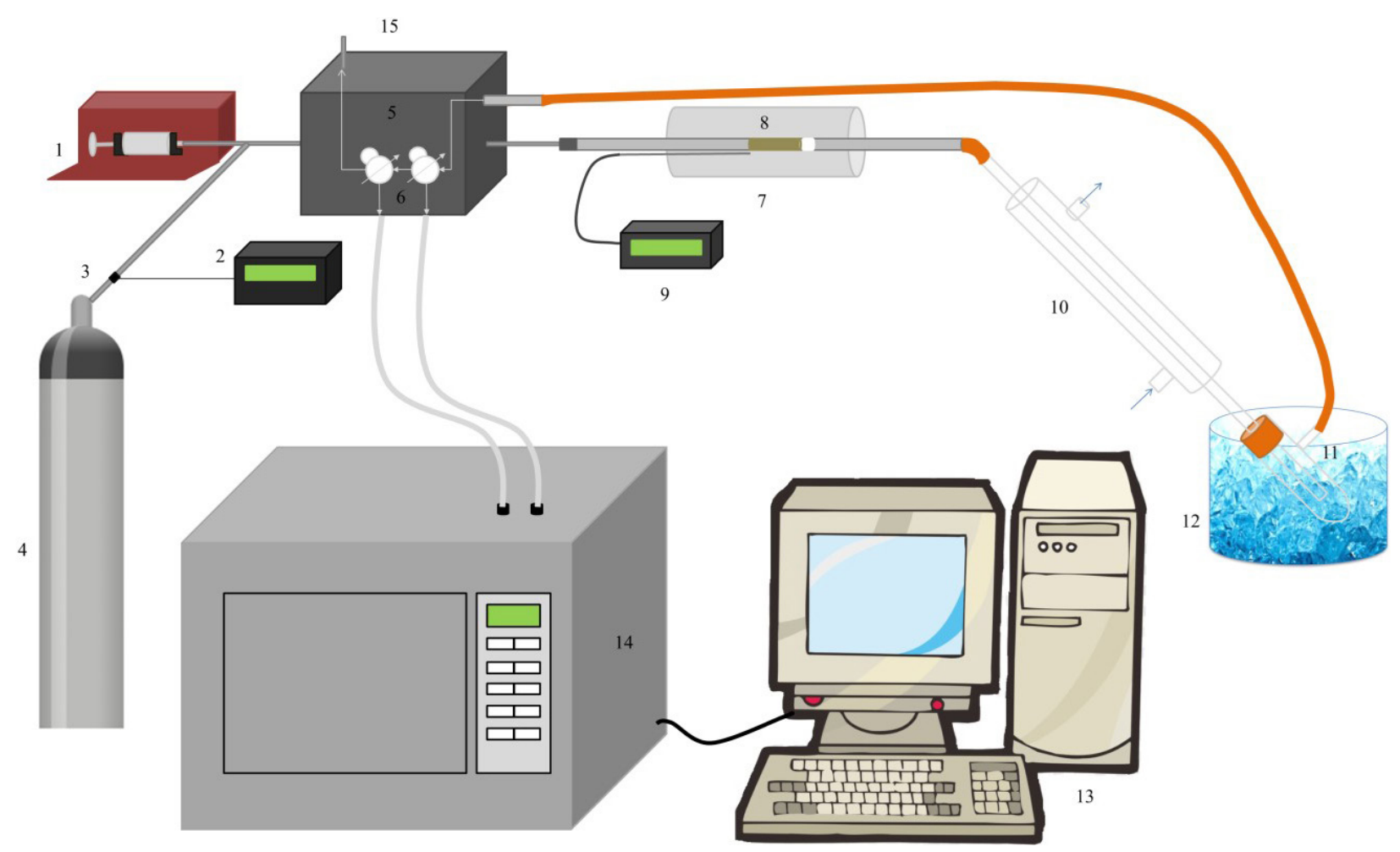

Fig. 2. Scheme of the apparatus for catalytic tests: 1 syringe pump; 2 PID controller; 3 solenoid valve; 4 nitrogen cylinder; 5 heated chamber; 6 six-way valves; 7 reactor; 8 catalyst in the reactor; 9 temperature controller; 10 condenser; 11 liquid products collector; 12 pot with ice; 13 computer; 14 gas chromatograph; 15 off-gas. 
nol, were cooled by a condenser. Liquid products were collected in a refrigerated flask and analyzed using a Shimadzu QP-2010 Ultra GC/MS. Gaseous products were analyzed by GC equipped with a packed Porapak $Q$ column and a FID detector connected on-line via a 6 -way valve (Fig, 2). The yields of the products (estimating the expansion factor of the reaction mixture to be near zero) were calculated as molar per cents:

$$
\begin{aligned}
& Y_{C 2}=\frac{c_{C 2}}{c_{E t O H}} \\
& Y_{C 3}=\frac{1.5 c_{C 3}}{c_{E t O H}} \\
& Y_{C 4}=\frac{2 c_{C 4}}{c_{E t O H}}
\end{aligned}
$$

where C2, C3, C4 stand for the particular C2, C3, C4 hydrocarbons; factors 1.5 and 2 reflect the ratio of carbons in $\mathrm{C} 3$ and $\mathrm{C} 4$ to $\mathrm{C} 2$. $\mathrm{C}_{\mathrm{EtOH}}$ is the molar concentration of ethanol vapors at the inlet of the reactor; concentrations of hydrocarbons were determined using direct calibration method.

\section{Results and discussion}

\section{Zeolite-based catalysts}

Acid-catalyzed dehydration of ethanol has been well documented (Tarach et al., 2016). Zeolites in $\mathrm{H}$-form represent strong solid acids, thus, massive dehydration of ethanol over parent zeolites is not surprising (Bi et al., 2010). Ethylene yields of up to $90 \%$ even at relatively low temperatures were observed using several commercial types of zeolites (BEA(12), ZSM-5(15), not listed). In our previous work, beneficial effect of magnesium promoters in several types of zeolites was reported (Godová et al., 2018). Magnesium is supposed to neutralize the acidic sites in zeolites. Suppressed formation of ethylene was observed at lower temperatures $\left(300{ }^{\circ} \mathrm{C}\right)$, however at higher temperatures (above $400{ }^{\circ} \mathrm{C}$ ), ethylene dehydration was the most dominant reaction pathway in most cases.
To further elucidate the possibility of catalytic performance improvement, several types of zeolitic catalysts were prepared: unmodified MCM-22 and USY: modules 15 and 2.6, respectively, Y13 $5 \mathrm{Mg}-5 \mathrm{Zn}$, and $\mathrm{Y} 13-5 \mathrm{Cu}-5 \mathrm{Zn}$. Yields of the main reaction products are summarized in Tab. 2 at the selected reaction temperature of $400^{\circ} \mathrm{C}$.

As it can be seen in Tab. 2, MCM-22, Y13 and USY zeolites themselves efficiently catalyze ethylene formation (with yields: $31.5 \%, 47.2 \%$ and $35.3 \%$, respectively) by simple dehydration of ethanol, however, they perform poorly in the formation of higher hydrocarbons (yields below $5 \%$ ). USY, with acidity more than three times higher than that of MCM-22, produces a little more ethylene and at the same time MCM-22 produces more butadiene. This phenomenon due to ethylene formation being acid catalyzed, but excessive acidity is disadvantageous for the formation of butadiene (see Tab. 1 and 2).

For Y13, copper, as expected, enhanced the ethanol dehydrogenation to acetaldehyde, improving the acetaldehyde yield to $22.7 \%$ in contrast with $1.4 \%$ obtained with undoped catalyst. Magnesium, a basic component, suppressed the acid-catalyzed formation of ethylene, leading to a significant drop in its yields (47.2\% for the undoped sample to $14.3 \%$ for the doped one). Considering the yields of other hydrocarbons (with the emphasis on the most desired butadiene), these promoters themselves do not significantly increase their production (from $1.8 \%$ to $2.3 \%$ butadiene yield for the $\mathrm{Mg}$-doped sample and from $1.8 \%$ to $4.0 \%$ for the Cu-doped one). In case of the $\mathrm{Cu}$-doped sample, the increase in the butadiene yield corresponds with the increased formation of acetaldehyde (from $1.4 \%$ to $22.7 \%$ ). The presence of copper led to a significant 16 -fold increase in the acetaldehyde yield. Acetaldehyde is a precursor for the production of butadiene. In comparison with the 16-fold increase in the acetaldehyde yields, only a ca. two-fold increase in the butadiene yields were observed. Hence, copper on the Y13 catalyst failed to promote further acetaldehyde reactions, leaving significant amounts of unreacted acetaldehyde.

Table 2: Yields of the main reaction products (in mol \%) over selected zeolytic catalysts.

\begin{tabular}{lcccc}
\hline Catalyst / yields mol \% & ethylene & propylene & butadiene & acetaldehyde \\
\hline MCM-22 & 31.5 & 4.2 & 1.6 & 8.8 \\
USY & 35.3 & 2.5 & 0.8 & 5.2 \\
Y13 & 47.2 & 3.5 & 1.8 & 1.4 \\
Y13 - 5Mg & 14.3 & 2.6 & 2.3 & 9.7 \\
Y13 - 5Cu & 38.8 & 4.8 & 4.0 & 22.7 \\
Y13 - 5Mg-5Zn & 12.7 & 8.2 & 12.6 & 6.7 \\
Y13 - 5Cu - 5Zn & 35.5 & 7.2 & 18.5 & 7.4 \\
\hline
\end{tabular}


Zinc was found to promote the formation of heavier hydrocarbons both over $\mathrm{Mg}$ - and $\mathrm{Cu}$ - doped catalysts, the highest yield of butadiene, 18,5\%, was observed over the Cu-doped catalyst, which however did not lead to a decrease in ethylene formation (decrease only by ca. $3 \%$ ). The increase in the butadiene yield, again, corresponds with the decrease in acetaldehyde content in the reaction products. These observations imply the existence of two different consecutive reaction paths necessary for increased butadiene formation: acetaldehyde formation, acetaldehyde consumption to form butadiene.

\section{Hydrotalcite-based catalysts}

Hydrotalcites were prepared by precipitation with $\mathrm{Na}_{3} \mathrm{CO}_{3}$ at constant $\mathrm{pH}=10$ and by precipitation in the presence of urea. The difference between these methods is that the precipitate is formed almost immediately in the precipitation with $\mathrm{Na}_{2} \mathrm{CO}_{3}$ in the presence of $\mathrm{NaOH}$, while urea slowly hydrolyzes to form $\mathrm{NH}_{3}$ which gradually precipitates hydrotalcite. This is also reflected in the morphology of the precipitate formed. Precipitation with urea results in a rather regular lamellar structure typical of hydrotalcite; however, precipitation with $\mathrm{Na}_{2} \mathrm{CO}_{3}$ gave an irregular morphology with only a slight or no indication of lamellar structures (compare Figures 3 and 4).

On the other hand, both samples have an XRD pattern typical of hydrotalcites (Fig. 5) indicating the hydrotalcite crystal structure in both precipitates, although an organized morphology is far from being formed in case of precipitation with $\mathrm{Na}_{2} \mathrm{CO}_{3}$ (Fig. 4).

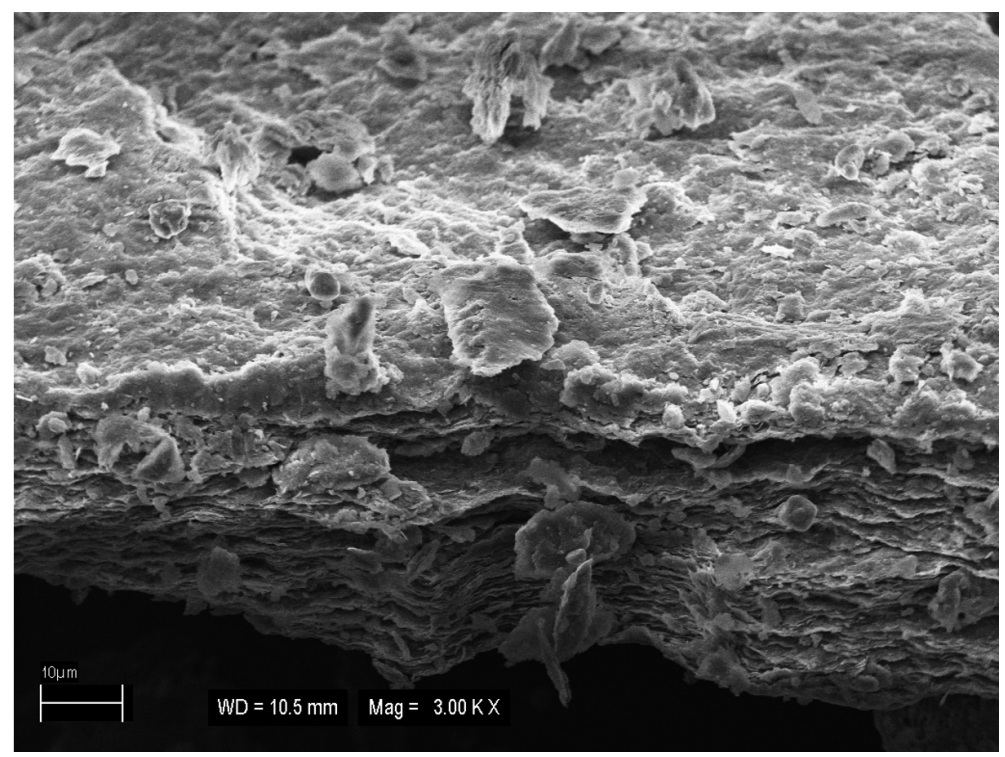

Fig. 3. SEM image of hydrotalcite prepared by urea hydrolysis method.

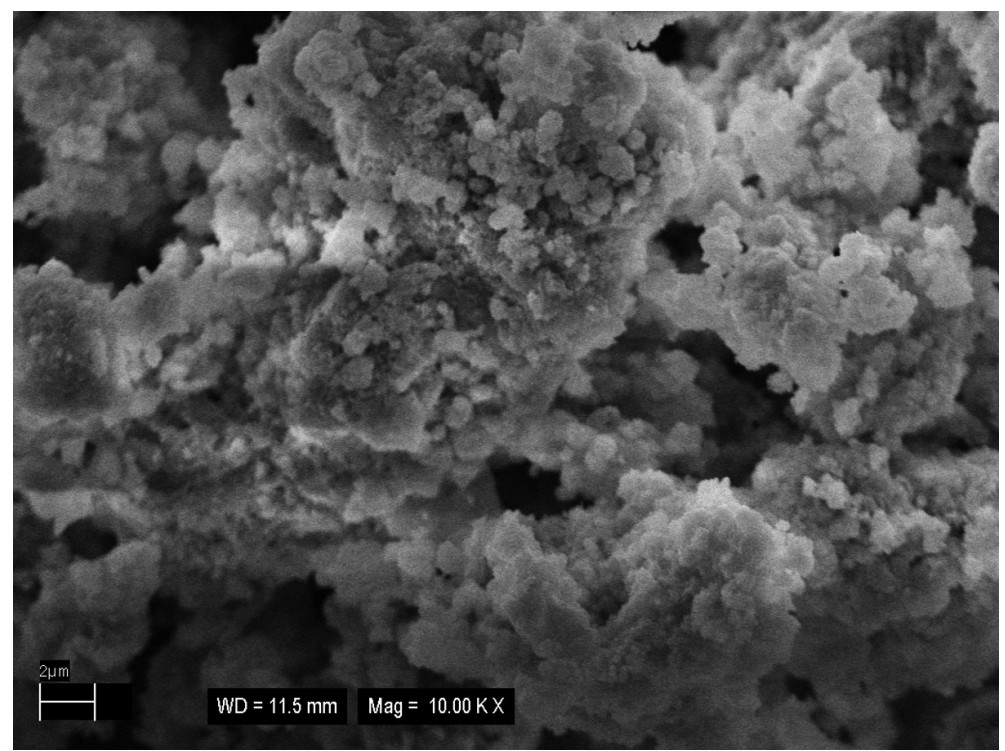

Fig. 4. SEM image of hydrotalcite prepared by precipitation with $\mathrm{Na}_{2} \mathrm{CO}_{3}$. 
According to Constantine et al. (1995), the values of lattice parameters $a$ and $c$ can be determined from X-ray patterns. Parameter $a$ corresponds to the cation-cation distance inside the "brucite" layer and can be calculated as $a=2 \times \mathrm{d}(110)$ (Shekoohi et al., 2017). Parameter $c$ corresponds to the thickness of the "brucite" layer and can be determined as $c=3 \times \mathrm{d}(003)$ (Shekoohi et al., 2017). In some papers, parameter $c$ determines distances between "brucite" layers and is calculated as c $=(\mathrm{d}(003)+2 \times$ $\times \mathrm{d}(006)) / 2$ (Aramendia et al,. 2002). Particle sizes are frequently determined just from X-ray patterns using the Scherrer equation. Hence, in many literature sources, the Scherrer-size pretends to be the exact particle size (e.g., Aramendia et al., 2002). However, as the particles can be composed of several crystallites, such an estimation of the particle size may not be correct. Therefore, to evaluate the size and shape of catalyst particles, we rely on SEM scans rather than on the Scherrer equation.

Using known radiation wavelength, 2 theta values can be converted to particular values of $d$ in the Bragg's equation. Accordingly, values of $d(003)$ and $\mathrm{d}(110)$ for hydrotalcite prepared by urea hydrolysis equal to $0.78 \mathrm{~nm}$ and $0.15 \mathrm{~nm}$, respectively. This corresponds to parameters $a=0.30 \mathrm{~nm}$ (distance between cations) and $c=2.34 \mathrm{~nm}$ (distance between layers). The value of parameter $c$ is in good accordance with that of nano-hydrotalcites at the Mg:Al ratio of 3:1 (Shekoohi et al., 2017). This parameter, however, depends on the nature and ratio of $\mathrm{M}^{2+} / \mathrm{M}^{3+}$ cations as well as on the nature of interlayer anions.

There is a well-documented phenomenon called "memory effect" of hydrotalcites (Palomaresa et al., 2004). Upon calcination at $450{ }^{\circ} \mathrm{C}$, XRD

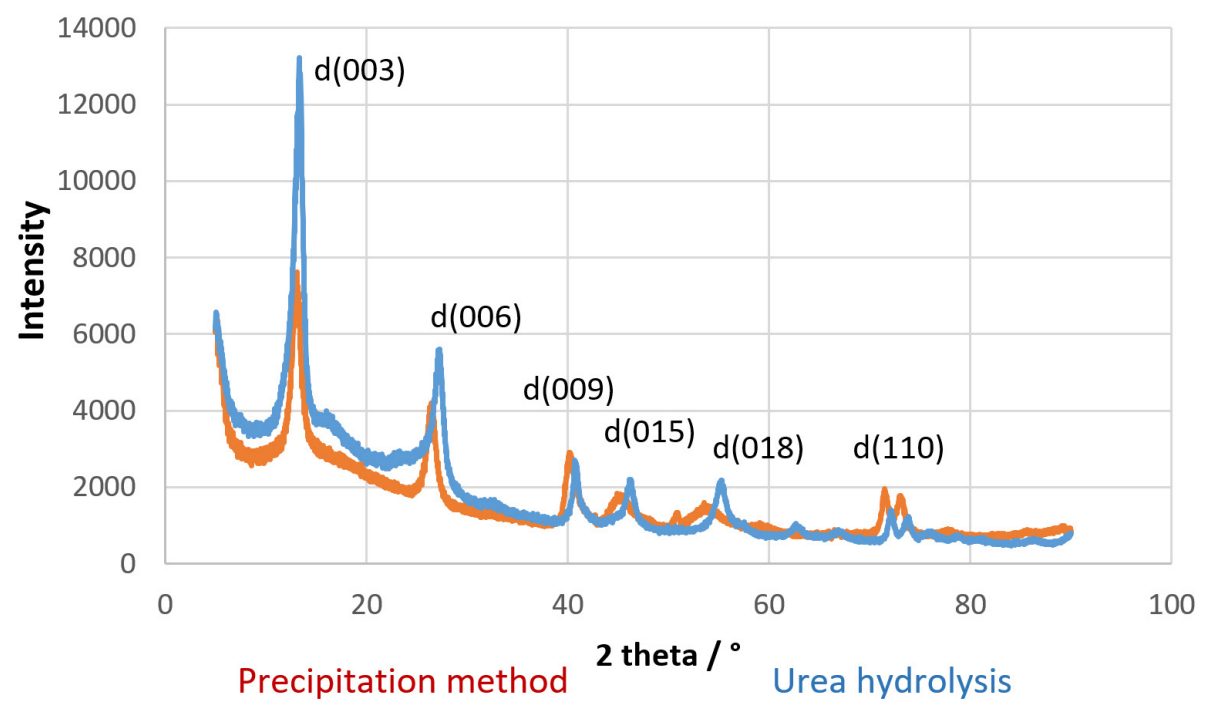

Fig. 5. XRD patterns of samples prepared by precipitation with $\mathrm{Na}_{2} \mathrm{CO}_{3}$ and urea.

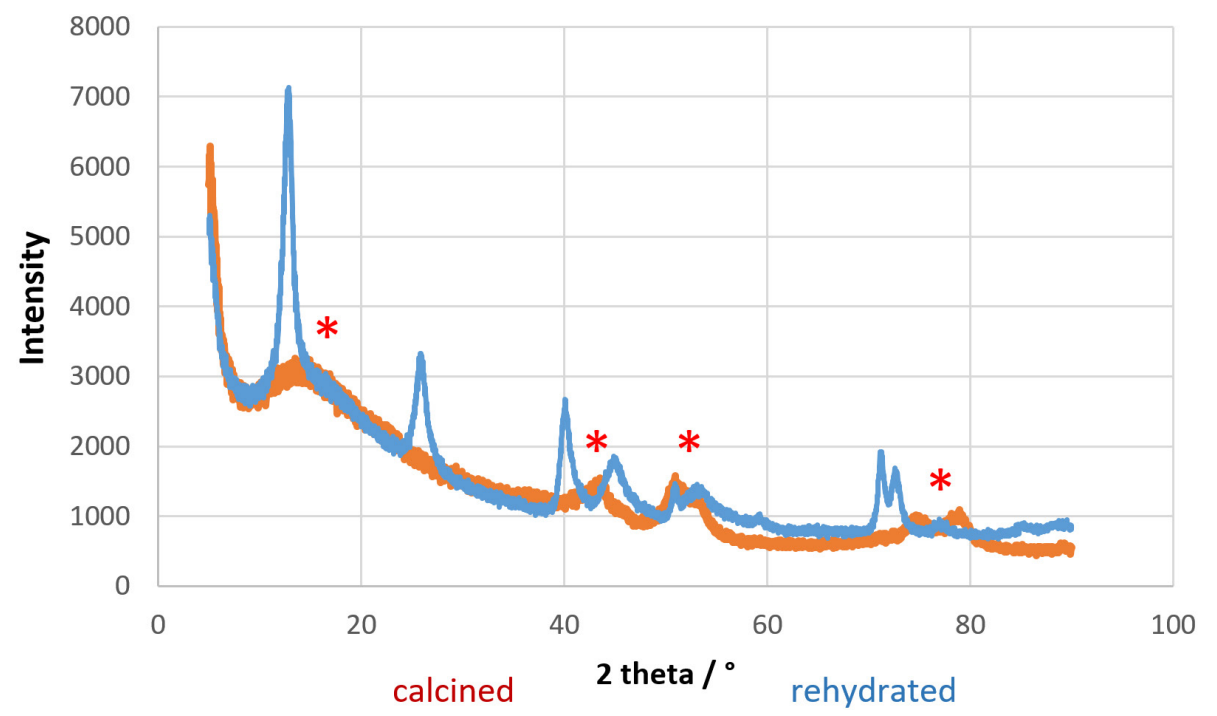

Fig. 6. XRD patterns of calcined and rehydrated hydrotalcite originally prepared by precipitation. 


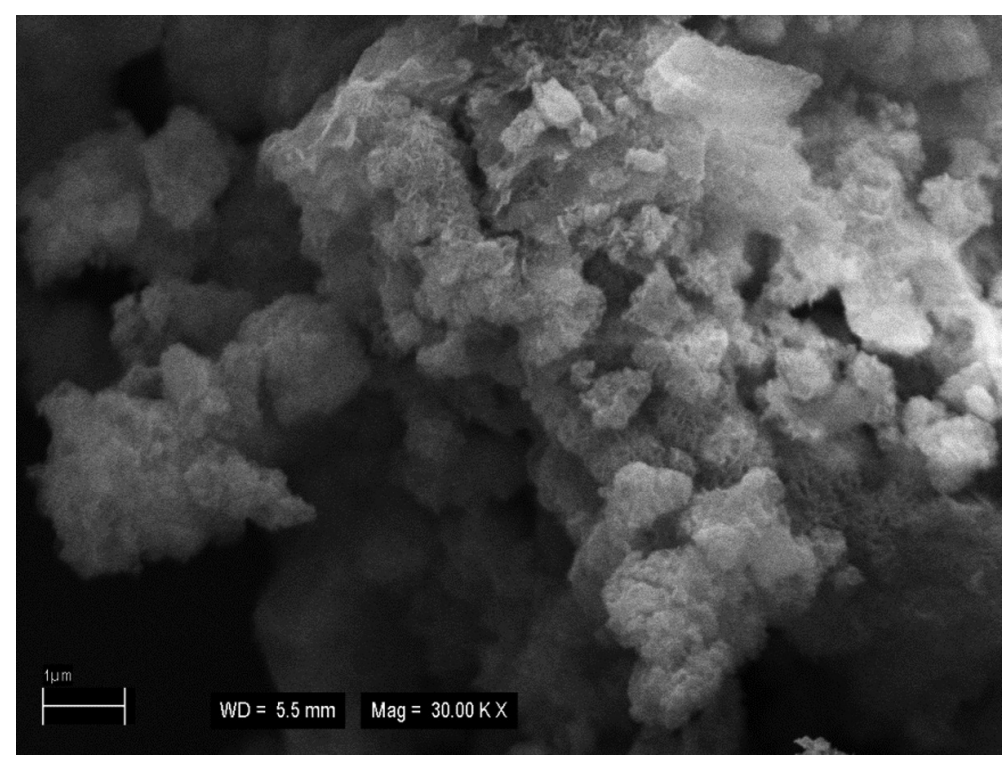

Fig. 7. SEM image of hydrotalcite prepared by dehydratation and subsequent rehydration.

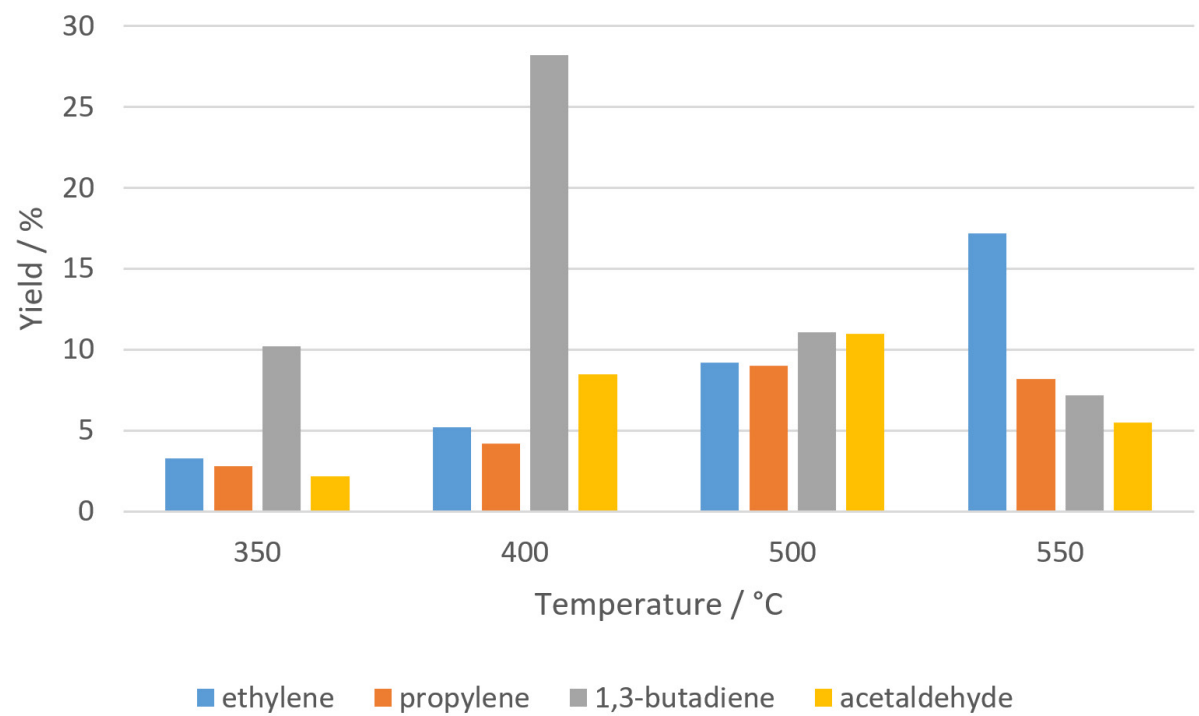

Fig. 8. Catalytic performance of hydrotalcite prepared by the urea method.

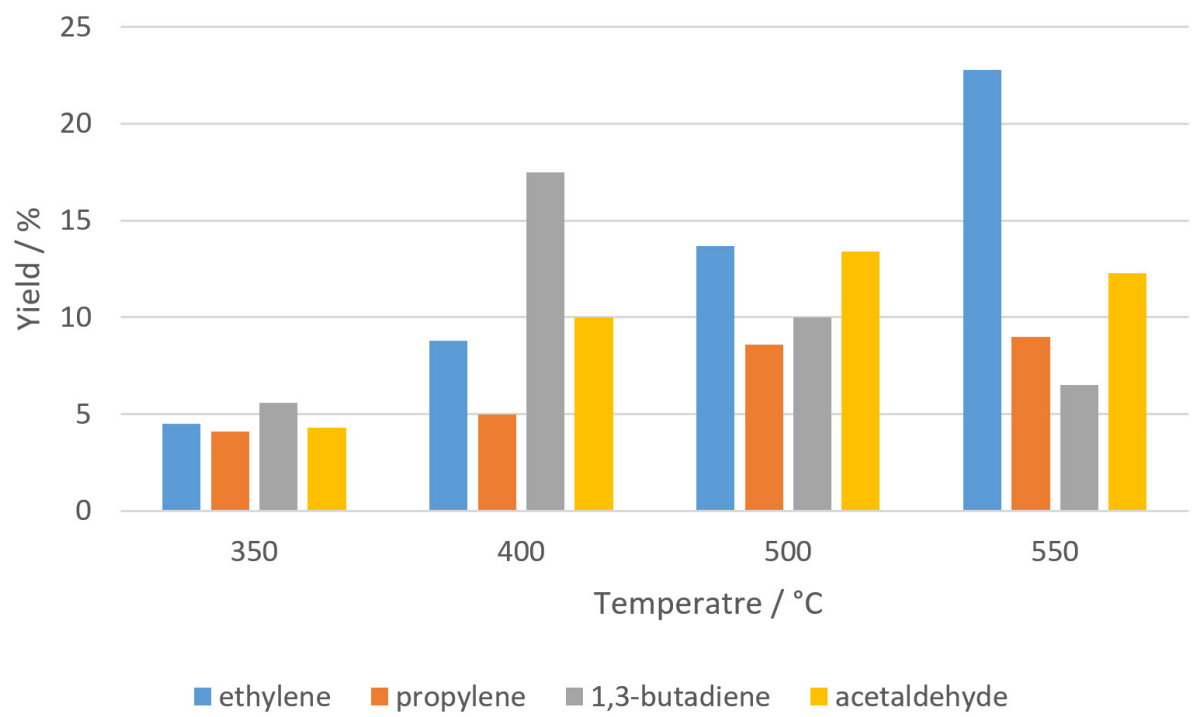

Fig. 9. Catalytic performance of hydrotalcite prepared by precipitation with $\mathrm{Na}_{2} \mathrm{CO}_{3}$. 
structure of hydrotalcites is lost which results in $\mathrm{Al}-\mathrm{Mg}$ mixed oxides. However, when exposed to humidity and $\mathrm{CO}_{2}$, reorganization of the original hydrotalcite structure occurs. Fig. 6 shows that the original structure of the hydrotalice was lost upon calcination, resulting in a mostly XRD-amorphous material. Broad peaks in the calcined material (*), according to the Scherrer's law, indicate poor crystalline structure. After rehydration, the mostly amorphous mixed oxides regained their XRD structure typical for hydrotalcites.

However, the typical lamellar structure of hydrotalcite did not form. Comparing Fig. 4 and Fig. 7, only a minor part of the bulky material formed small lamellae typical for hydrotalcites after rehydration.

Correlation between the preparation method and catalytic activity of these hydrotalcites was observed.
At the reaction temperature of $500{ }^{\circ} \mathrm{C}$ and above, butadiene yields were significantly reduced and hence it can be concluded that the loss of the hydrotalcite structure is not beneficial for butadiene formation. It has also been found that the highest butadiene yields are obtained over a catalyst with regularly developed lamellar structure, which indicates that good catalytic activity depends not only on the ratio of $\mathrm{Mg}$ : Al corresponding to hydrotalcite but also the catalyst nanostructure is important. Correspondingly, the sample prepared by the urea method provided increased butadiene yield, most significantly at the reaction temperature of $400{ }^{\circ} \mathrm{C}$ (Figs. 8 and 9).

When compared with the parent catalyst (used in the experiment in Fig. 9), the dehydration-rehydration procedure did not significantly affect the butadiene yields but resulted only in a slight (from

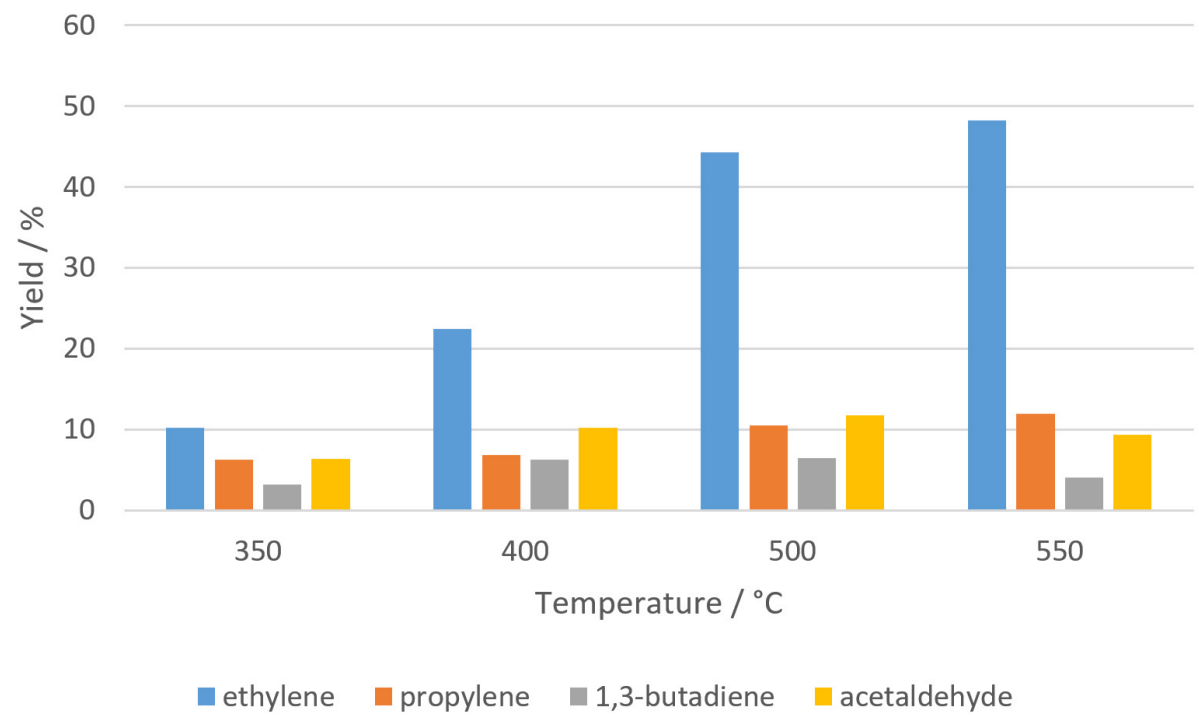

Fig. 10. Catalytic performance of the precipitate using $\mathrm{Mg}: \mathrm{Al}$ ratio of 0.5:1 in the precursors.

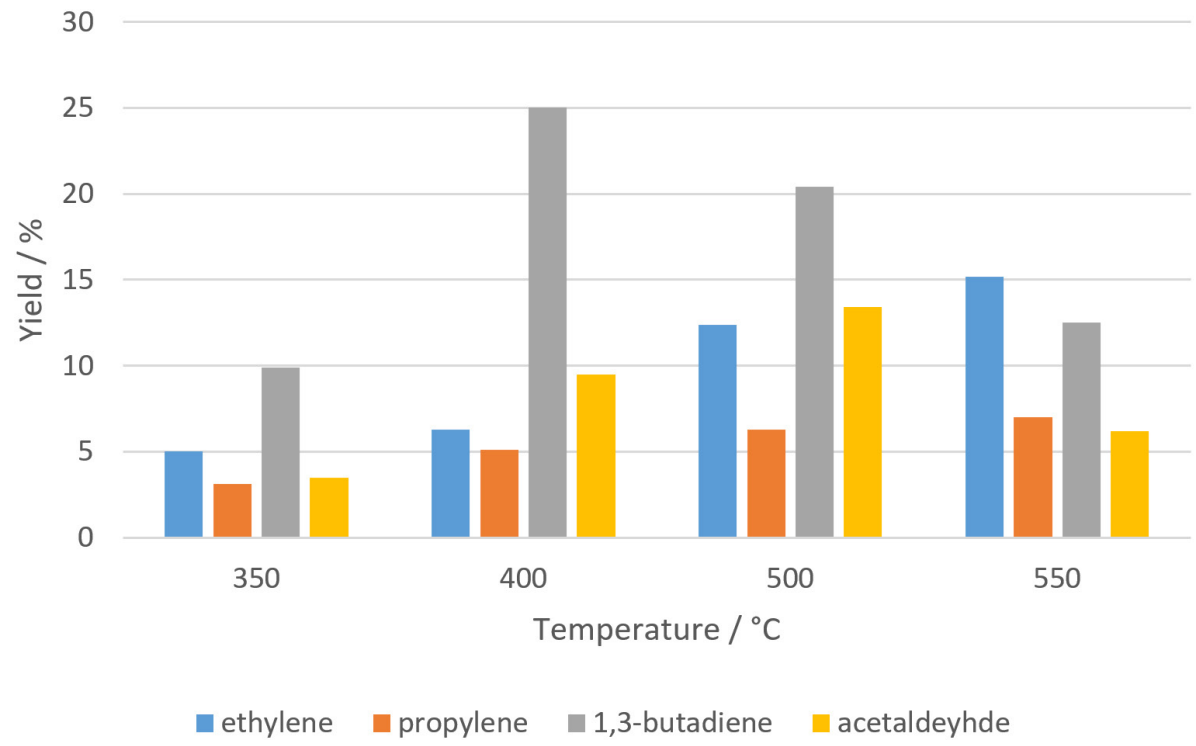

Fig. 11. Catalytic performance of Pluronic-templated hyrotalcite. 
$10 \%$ to $12 \%$ ) increase in the acetaldehyde yield at $400{ }^{\circ} \mathrm{C}$. However, as acetaldehyde is a precursor of butadiene, promotion of its formation is desired. In the next step, a material with different $\mathrm{Mg}$ : $\mathrm{Al}$ ratio $(0.5: 1)$ was prepared by the $\mathrm{Na}_{2} \mathrm{CO}_{3}$ precipitation method. An excess of aluminum leads to basicity suppression (increase in acidity) compared to a typical HT material ( $\mathrm{Mg}: \mathrm{Al}=3: 1)$. The increased acidity enhanced the dehydration properties of the catalyst, while ethylene was formed at higher extent (Fig. 10) in comparison with the typical HT catalyst. Since precipitation with $\mathrm{Na}_{2} \mathrm{CO}_{3}$ did not lead to the formation of an ordered lamellar hydrotalcite structure, a pore-forming agent, Pluronic123, was used. It has been found that the addition of a poreforming agent has a beneficial effect on butadiene yields (Fig. 11). Thus, it can be concluded that structure-directed synthesis of hydrotalcites (either creating a lamellar structure or using a soft template Pluronic123) shifts the product distribution toward the most desired product, butadiene, while suppressing the formation of the least desired ethylene.

\section{Sepiolite-based catalysts}

Mixed $\mathrm{MgO}-\mathrm{SiO}_{2}$ oxides were repeatedly reported as catalysts for ethanol transformation to butadiene (Zhu et al., 2016). Sepiolite, a hydrous magnesium silicate clay mineral, formally $\mathrm{Mg}_{4} \mathrm{Si}_{6} \mathrm{O}_{15}(\mathrm{OH})_{2} \cdot 6 \mathrm{H}_{2} \mathrm{O}$, can be considered as a promising catalyst for ethanol transformation. Parent sepiolite as well as $\mathrm{K}, \mathrm{Sr}$ and Mn - doped samples were tested (5\% of dopant, calculated as weight \% of the corresponding metal oxide). Catalytic activity of the parent sepiolite was low compared to that of hydrotalcites (Fig. 12). Moreover, the main reaction product was ethylene.

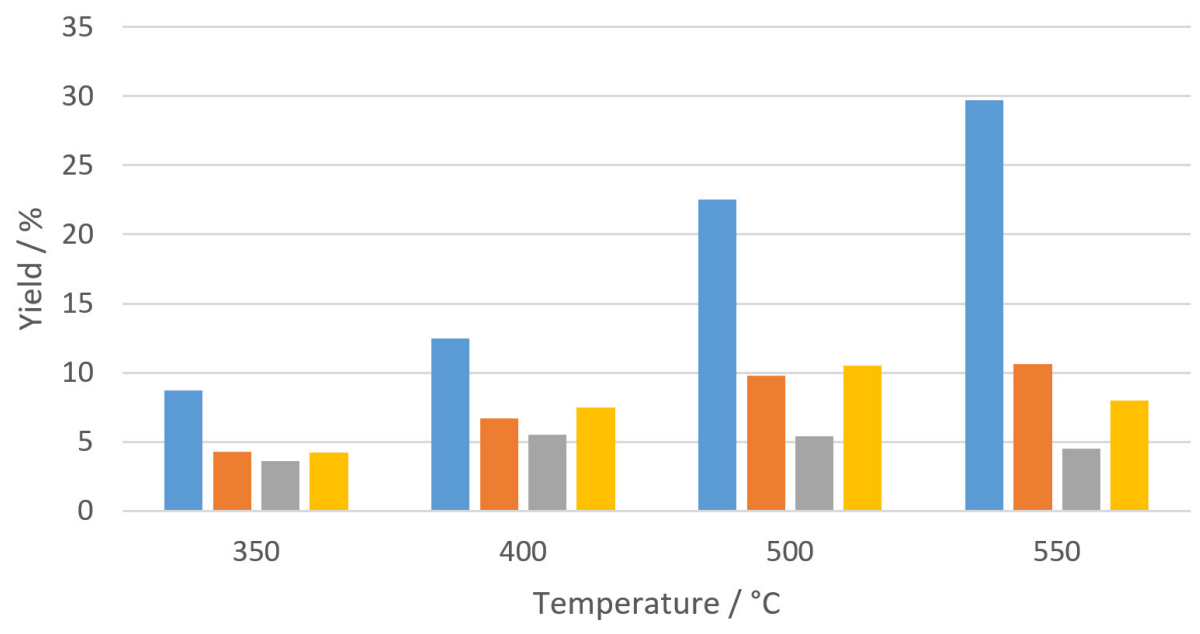

" ethylene $\square$ propylene $\square$ 1,3-butadiene $\square$ acetaldehyde

Fig. 12. Catalytic performance of parent sepiolite.

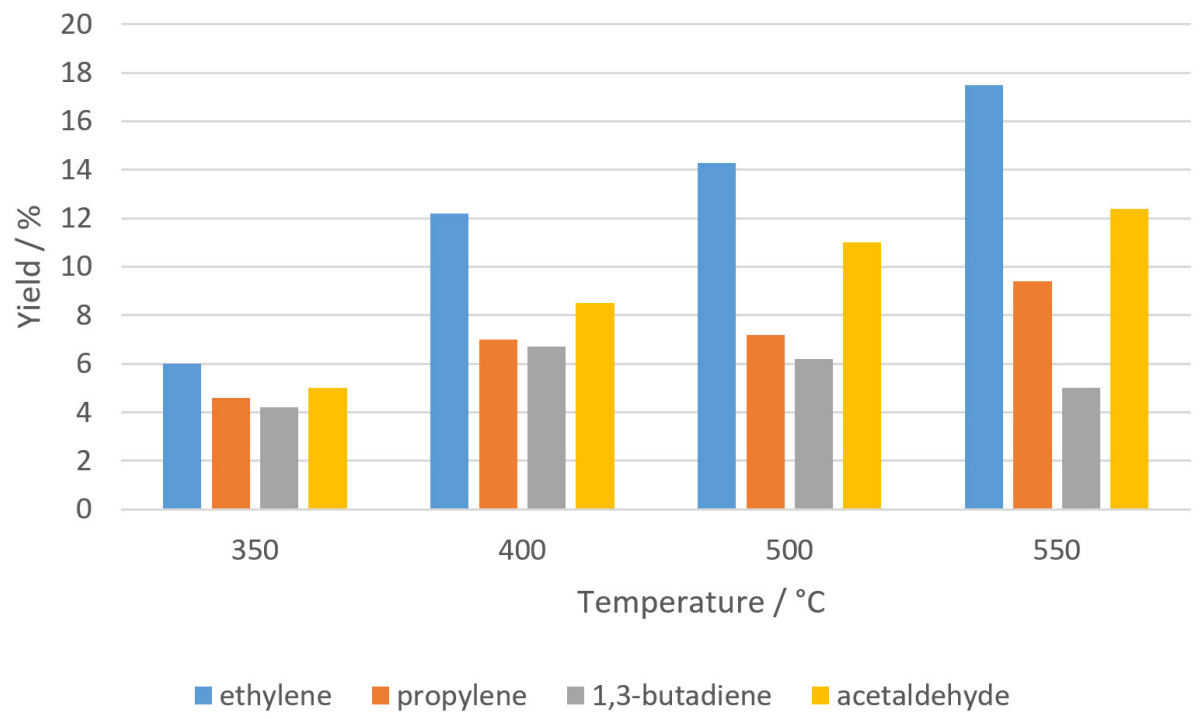

Fig. 13. Catalytic performance of K-promoted sepiolite. 


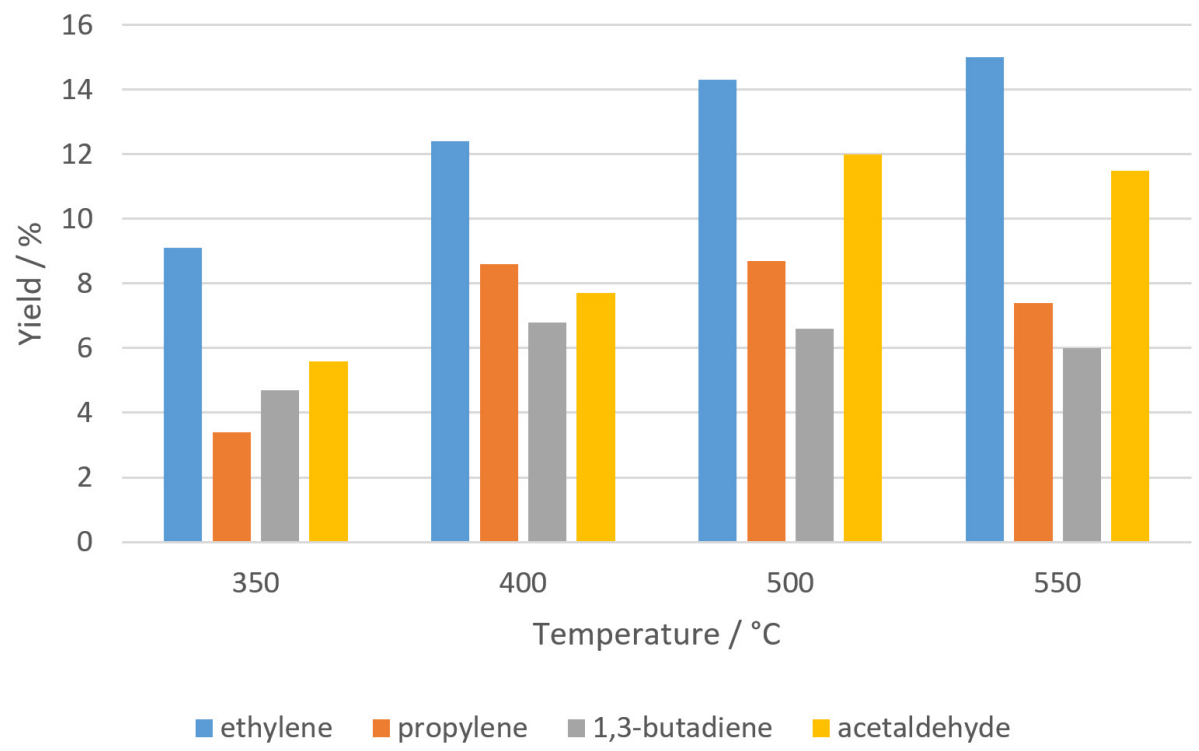

Fig. 14. Catalytic performance of Sr-promoted sepiolite.

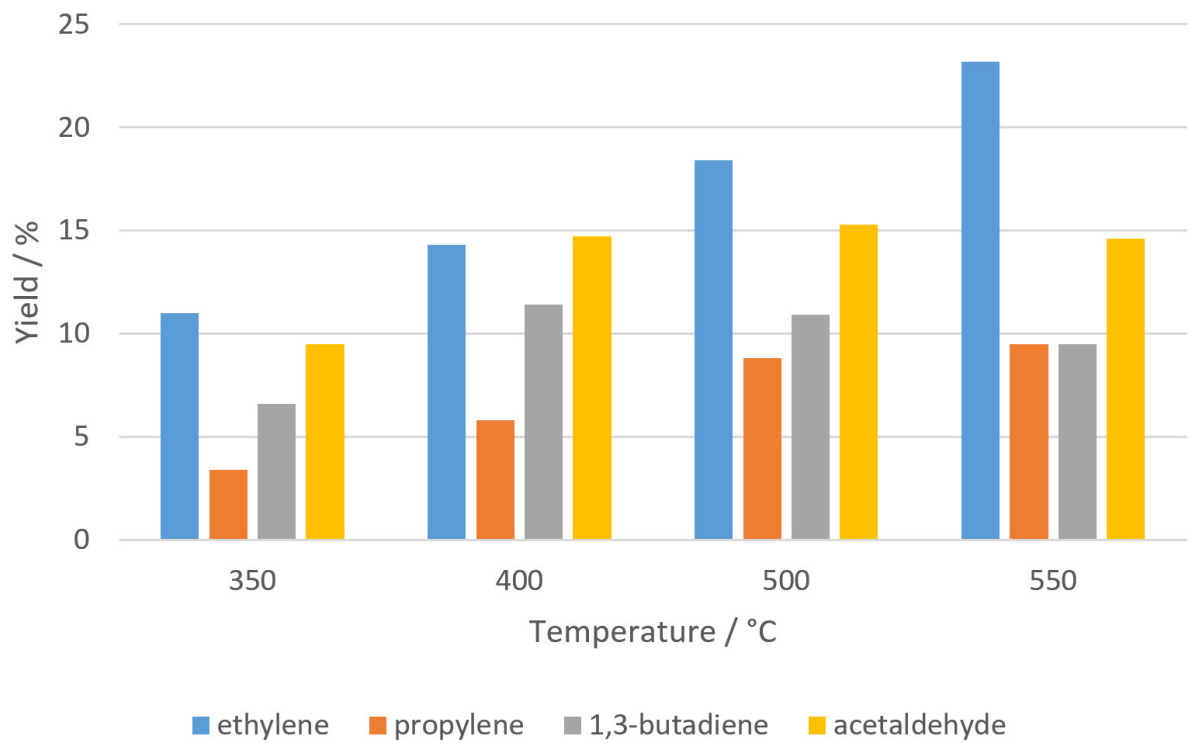

Fig. 15. Catalytic performance of Mn-promoted sepiolite.

To increase the basicity, $\mathrm{K}$ and $\mathrm{Sr}$ were used as basic promoters; they suppressed ethylene formation (Figs. 13 and 14). However, no increase in the butadiene formation was observed. Addition of Mn led to an increase in the acetaldehyde yield and a ca. two-fold increase in butadiene yields compared to the Mn-free samples (Fig. 15).

\section{Conclusions}

Catalytic tests with hydrotalcites, sepiolites, and zeolites doped with $\mathrm{Cu}, \mathrm{K}, \mathrm{Sr}, \mathrm{Zn}$ and $\mathrm{Mn}$ were carried out in ethanol transformation to higher value products in a plug-flow reactor in the temperature range of $350-550{ }^{\circ} \mathrm{C}$. Undoped zeolites were found to promote the acid-catalyzed dehydration of ethanol, while basic catalysts, such as hydrotalcites, shifted the product distribution toward butadiene. The main drawback of zeolites' utilization for the catalytic transformation of ethanol to alkenes is their high activity in ethanol dehydraton to ethylene. While bioethylene is of industrial interest, its production is not limited to ethanol as the bio-resource. Therefore, propylene and especially butadiene have been studied. Zinc was found to promote the formation of heavier hydrocarbons both over $\mathrm{Mg}$ - and $\mathrm{Cu}$ doped zeolites. These products cannot be obtained by simple dehydration of ethanol; their formation requires several reaction steps.

Non-zeolytic nanostructured materials were found to be promising catalysts for bioethanol transformation to valuable chemicals with emphasis on light alkenes. It was found that hydrotalcite with well-developed layered structure, prepared by slow 
hydrolysis, promotes butadiene formation (with butadiene yield of $28.2 \%$ at $400{ }^{\circ} \mathrm{C}$, vs. ethylene yield of $17.2 \%$ at $550{ }^{\circ} \mathrm{C}$ ). Simple precipitation failed to generate pronounced layered structure and led to worse catalytic performance (butadiene yield of $6.5 \%$ at $450{ }^{\circ} \mathrm{C}$, vs. ethylene yield of $48.2 \%$ at $\left.550^{\circ} \mathrm{C}\right)$.

\section{Acknowledgement}

This work was supported by the Slovak Research and Development Agency under the Contract no. APVV 17 . 0302.

\section{References}

Akiyama S, Miyaji A, Hayashi Y, Hiza M, Sekiguchi Y, Koyama T, Baba T (2018) Journal of Catalysis, 359: 184-197.

Aramendia MA, Borau V, Jimenéz C, Marinas JM, Ruiz JR, Urbano FJ (2002) Journal of Solid State Chemistry, 168: 156-161.

Basahel SN, Al-Thabaiti SA, Narasimharao K, Ahmed NS, Mokhtar M (2014) Journal of Nanoscience and Nanotechnology, 14(2): 1931-1946.

Benhiti R, Ait Ichou A, Zaghloul A, Aziam R, Carja G, Zerbet M, Sinan F, Chiban M (2020) Environmental Science and Pollution Research, 27: 45767-45774.

Bi J, Guo X, Liu M, Wang X (2010) Catalysis Today 149: 143-147.

Constantino VRL, Pinnavaia TJ (1995) Journal of Inorganic Chemistry 34(4): 883-892.

Corson BB, Jones HE, Welling CE, Hinckley JA, Stahly EE (1950) Industrial and Engineering Chemistry, 42: 359-373.

Egloff G, Hulla G (1945) Chemical Reviews, 36: 63-141.

Gao M, Jiang H, Zhang M (2018) Applied Surface Science, 439: 1072-1078.

Godová N, Horváth B (2018) Acta Chmica Slovaca, 11(1): $11-20$.

Jones HE, Stahly EE, Corson BB (1949) Journal of the American Chemical Society, 71: 1822-1828.

Kampmeyer PM, Stahly EE (1949) Industrial and Engineering Chemistry, 41: 550-555.

Klein A, Palkovits RRP (2017) Catalysis Communications, 91: 72-75.
Kyriienko PI, Larina OV, Soloviev SO, Orlyk SM, Calers C, Dzwigaj S (2017) ACS Sustainable Chemistry \& Engineering, 5(3): 2075-2083.

Lebedev SV (1929) GB Patent GB 331482.

León M, Díaz E, Ordóñez S (2011) Catalysis Today, 164(1): 436-442.

Li S, Men Y, Wang J, Liu S, Song Q (2019) Applied Catalysis A, General, 577: 1-9.

Palomaresa AE, Prato JG, Rey F, Corma A (2004) Journal of Catalysis, 221(1): 62-66.

Pampararo G, Garbarino G, Riani P, Garcia MV, Escribano VS, Busca G (2020) Applied Catalysis A, General, 602: 117710.

Pomalaza G, Arango P, Capron M, Dumeignil F (2020) Catalysis Science \& Technology 10: 4860-4911.

Prinetto F, Ghiotti G, Graffin P, Tichit D (2000) Microporous and Mesoporous Materials, 39(1-2): 229-247.

Rackley SA (2017) Carbon Capture and Storage $2^{\text {nd }}$ Edition, Butterworth-Heinemann: 151-185.

Rao MM, Reddy BR, Jayalakshmi M, Jaya VS, Sridhar B (2005) Materials Research Bulletin, 40(2): 347-359.

Sekiguchi Y, Akiyama S, Urakawa W, Koyama T, Miyaji A, Motokura K, Baba T (2015) Catalysis Communication, 68: 20-24.

Shekoohi K, Hosseini FS, Haghighi AH, Sahrayian A (2017) MethodsX 4: 86-94.

Sikander U, Sufian S, Salam MA (2017) International Journal of Hydrogen Energy, 42(31): 19851-19868.

Soták T, Magyarová Z, Shamzhy M, Kubů M, Gołąbek K, Čejka J, Hronec M (2021) Applied Catalysis A, General, 618: 118122.

Szabó B, Novodárszki G, May Z, Valyon J, Hancsók J, Barthos R (2020) Molecular Catalysis 491: 110984.

Tarach KA, Tekla J, Makowski W, Filek U, Mlekodaj K, Girman V, Góra-Marek K (2016) Catalysis Science \& Technology, 6(10): 3568-3584.

Tayrabekova S, Mäki-Arvela P, Peurla M, Paturi P, Eränen K, Ergazieva GE, Dossumov K (2018) Comptes Rendus Chimie, 21(3-4): 194-209.

Tian G, Han G, Wang F, Liang J (2019) Nanomaterials from Clay Minerals: A New Approach to Green Functional Materials, Elsevier: 135-201.

Zhao Y, Li S, Wang Z, Wang S, Wang S, Ma X (2019) Chinese Chemical Letters 31(2): 535-538.

Zhu Q, Wang B, Tan T (2016) ACS Sustainable Chemistry \& Engineering, 5(1): 722-733. 